\title{
Symplocos neblinae (Symplocaceae), um novo registro para a flora brasileira
}

\author{
Symplocos neblinae (Symplocaceae), a new record for the Brazilian flora
}

João Luiz M. Aranha Filho ${ }^{1,3}$, Cyl Farney Catarino de Sá ${ }^{2}$ \& Angela B. Martins ${ }^{1}$

\begin{abstract}
Resumo
O presente trabalho apresenta o primeiro registro de Symplocos neblinae para o Brasil. Esta espécie foi coletada no Pico da Neblina (Parque Nacional do Pico da Neblina), no estado do Amazonas. Nós fornecemos uma descrição e ilustração da espécie, notas de distribuição, hábitat, comparação com a espécie morfologicamente próxima, uma chave das espécies de Symplocos sérieSymplocos na Região Norte do Brasil e uma lista de espécimes examinados.

Palavras-chave: distribuição geográfica, flora amazônica, Pico da Neblina.
\end{abstract}

\begin{abstract}
This paper presents the first record of Symplocos neblinae for Brazil. This species was collected in Pico da Neblina (Pico da Neblina National Park) in the state of Amazonas. We provide a description and illustration of the species, notes on distribution, habitat, comparison with the closest morphologically related species, a key to the species of Symplocos series Symplocos in Northern Brazil, and a list of the specimens examined.

Key words: geographic distribution, Amazonian flora, Pico da Neblina.
\end{abstract}

\section{Introdução}

Symplocos Jacq., um dos dois gêneros da família Symplocaceae, compreende aproximadamente 318 espécies distribuídas principalmente nas zonas tropicais e subtropicais das Américas, sul e leste asiático e Australásia (Fritsch et al. 2008). No Brasil, ocorrem cerca de 40 espécies que são encontradas predominantemente na Mata Atlântica e no Cerrado das Regiões Sul e Sudeste (Bidá 1995; Aranha Filho et al. 2007).

Symplocos neblinae Maguire \& Steyerm., aqui reportada como nova para a flora brasileira, pertence ao grupo informal "Symplocastrum", com aproximadamente 143 espécies restritas à América tropical e incluído em Symplocos série Symplocos (sensu Fritsch et al. 2008). Espécies deste grupo podem ser reconhecidas pelo ovário ínfero, estames glabros, monadelfos e adnatos à corola nitidamente além da base da mesma (Fritsch et al. 2008).
Esta espécie havia sido coletada originalmente nas escarpas das regiões leste, norte, noroeste e oeste do Cerro de La Neblina, Amazonas, sudeste da Venezuela (Maguire \& Wurdack 1959; Maguire \& Huang 1978; Steyermark \& Berry 2005). O Cerro de la Neblina, situado aproximadamente em 050'00'N e 6558'58' $\mathrm{W}$, está quase que totalmente inserido na Venezuela e somente a sua parte sudeste penetra o Brasil; porção onde se localiza o Pico da Neblina ou Pico Phelps, no estado do Amazonas (Maguire \& Wurdack 1959; Renner 1989). Justamente no Pico da Neblina o segundo autor do presente trabalho coletou a espécie em questão, mostrando que ela ocorre também na porção sudeste do Cerro de la Neblina, em território brasileiro

Considerada restrita à Venezuela, S. neblinae não foi tratada e descrita por Bidá (1995), na última revisão de Symplocos para o Brasil, apesar de coletada no Brasil em 1985. Visando auxiliar na

\footnotetext{
'Universidade Estadual de Campinas, Depto. Biologia Vegetal, Instituto de Biologia, C.P. 6109, 13083-970, Campinas, SP, Brasil.

${ }^{2}$ Instituto de Pesquisas Jardim Botânico do Rio de Janeiro, R. Pacheco Leão 915, 22460-030, Rio de Janeiro, RJ, Brasil.

Autor para correspondência: aranhafilho@gmail.com
} 
identificação de futuras coletas de S. neblinae estamos aqui apresentando chave para as espécies de Symplocos série Symplocos ocorrentes na Região Norte do Brasil, e uma descrição completa e ilustração dessa espécie, já que a literatura a seu respeito é restrita à descrição de Maguire \& Huang (1978) e à chave de Steyermark \& Berry (2005), aplicável somente às 11 espécies ocorrentes na Guayana venezuelana.

\section{Material e Métodos}

Os herbários que tiveram suas coleções examinadas para a descrição de $S$. neblinae e para levantar as características das espécies utilizadas na chave foram: $\mathrm{A}^{*}, \mathrm{BHCB}, \mathrm{BM}^{*}, \mathrm{C}^{*}, \mathrm{CAS}, \mathrm{DS}$, ESA, F*, GH*, HRCB, IAC, K*, MBM, NY*, OUPR, RB, SP, SPF, UEC, UPCB, UPRRP* e US* (acrônimos conforme Thiers (2010), continuamente atualizado; siglas acompanhadas com asterisco tiveram as coleções examinadas por empréstimo via CAS, e aquelas sem asterico, os herbários foram visitados). O material coletado no Brasil pelo segundo autor foi incorporado ao herbário RB.

Informações sobre o hábito e altura de $S$. neblinae foram baseadas nas etiquetas dos materiais estudados e em Maguire \& Huang (1978). A terminologia utilizada na descrição e na chave foi a de Hickey (1973) e Hickey \& King (2000).

\section{Resultados e Discussão}

Symplocos neblinae Maguire \& Steyerm., Mem. New York Bot. Gard. 29: 229, figs. 119C-D, 110. 1978. Tipo: VENEZUELA. AMAZONAS: East escarpment to upper Cañon Grande Basin, 2200 m alt., Cerro de la Neblina, 13.XII.1957, fl. e fr., B. Maguire, J.J. Wurdack \& C.K. Maguire 42378 (holótipo NY!; isótipos US!, VEN).

Fig. 1

Arbusto a árvore, perenifólio, 2-8 m alt. Ramos marrom escuros ou marrom/vináceos, cilíndricos a levemente achatados, lisos, frequentemente fissurados transversalmente, esparsamente avermelhados ou alvo-estrigilosos, especialmente na porção terminal, glabrescentes. Folhas simples, alternas, sem estípulas, pecioladas; pecíolo adaxialmente canaliculado ou côncavo, (0,4-)0,6-1,5 cm compr., avermelhado ou alvo-estrigiloso, glabrescente; lâmina elíptica ou largo-elíptica, ocasionalmente largo-obovada ou suboblonga e raramente suborbiculada, 3,5-15,2× 1,3-8(-9) cm, cartácea ou coriácea, face abaxial alvoestrigilosa quando jovem, tornando-se glabra ou esparsamente estrigilosa na maturidade especialmente sobre a nervura mediana, face adaxial glabra, nervura mediana sulcada ao menos na metade proximal, venação obscuramente broquidódroma a semicraspedódroma, base atenuada ou cuneada, raramente subobtusa, margem suavemente revoluta a plana, inteira, ocasionalmente ondulada, glândulas maginais cedo caducas, ápice acuminado, raramente arredondado ou agudo, acúmen quando presente 0,4-1,8 cm compr. Inflorescência axilar, racemiforme, ocasionalmente paniculada, $0,4-1,5(-2,5) \mathrm{cm}$ compr., com 1 a 8 flores; pedúnculo $0,2-1,7 \mathrm{~cm}$ compr., esparso a densamente alvo-estrigiloso; brácteas cedo caducas (somente cicatrizes vistas). Flor bissexuada, 3,8-5,5 mm compr., séssil ou com pedicelo até $2 \mathrm{~mm}$ compr.; bractéolas 2 a 3 , geralmente persistentes no fruto, ascendentes a patentes, triangulares, obovadas ou ovadas, planas ou naviculares, $1-4 \times 0,5-1,5 \mathrm{~mm}$, externamente moderado a densamente alvo-estrigilosas, margem ciliolada; hipanto obcônico, 0,8-1,5 mm compr., densamente alvo-estrigiloso. Cálice gamossépalo, tubo ca. 0,2 mm compr., lobos 5, eretos a levemente ascendentes, triangulares a largo-ovalados, 0,9$1,5(-1,9) \times 0,8-1,5 \mathrm{~mm}$, externamente alvoestrigilosos principalmente ao longo da região mediana, margem ciliolada, eglandular a glândulas moderadamente distribuídas. Corola gamopétala, tubo 0,3-0,8 mm compr.; lobos 5 ou 6, alvos, 3-4,5 $\times 1,1-3 \mathrm{~mm}$, obovados, ovados ou elípticos, glabros, margem inteira, raramente esparso ciliolada. Estames 21 a 31, epipétalos, eretos a levemente arqueados para o interior da flor, em 3 a 5 séries de comprimento diferentes, monadelfos, tubo estaminal 0,3-0,7 mm compr.; filetes laminares, constritos no ápice, $0,5-$ 2,2 mm compr., glabros; anteras elipsóides a globosas, basifixas, \pm versáteis, $0,2-0,3 \times 0,2-$ $0,3 \mathrm{~mm}$, rimosas, latrorsas. Ovário ínfero, trilocular, placentação axilar, 2 a 4 óvulos por lóculo, inseridos na parte superior do ovário, pêndulos; disco curto-cilíndrico, piloso, anelar, ápice truncado a arredondado em vista longitudinal; estilete ereto, cilíndrico, 0,9-1,5(-2) mm compr., glabro; estigma discretamente lobado. Drupa elipsóide ou raramente subclaviforme, trilocular, frequentemente um dos lóculos notavelmente reduzido dando a impressão de ser bilocular, 0,85$1(-1,2) \times 0,45-0,65 \mathrm{~cm}$, esparsamente alvo-estrigilosa; ápice do fruto 2-3 mm diâm., não truncado; lobos do cálice conspícuos, eretos ao redor do disco; disco em forma de domo ou cônico, não excedendo o comprimento dos lobos do cálice, pubescente. Semente estriada, uma por lóculo. 


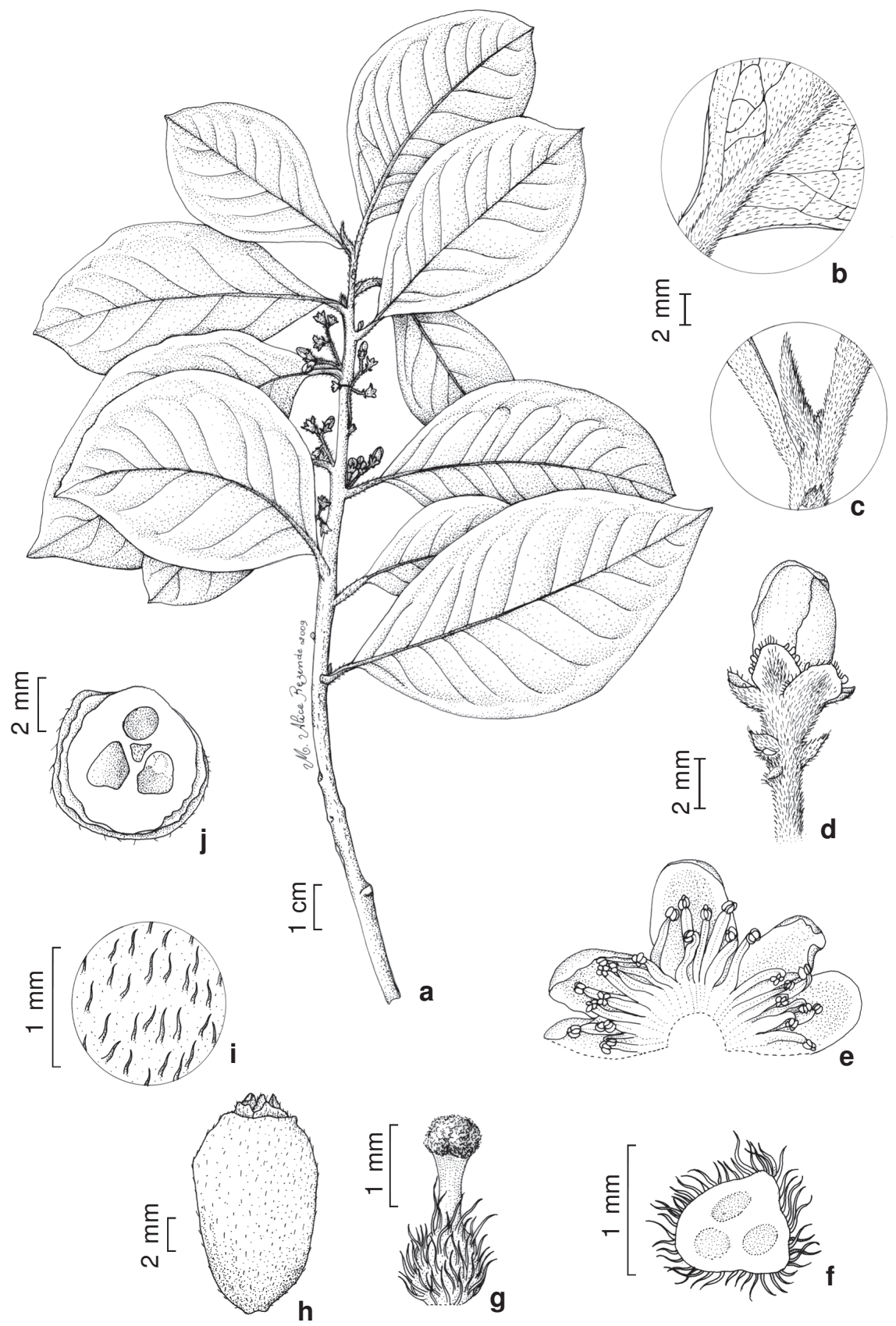

Figura 1 - Symplocos neblinae Maguire \& Steyerm. - a. ramo com flores; b. detalhe do indumento na folha jovem; c. detalhe do indumento nos ramos; d. botão floral; e. corola com estames epipétalos; f. secção transversal do ovário; g. ovário, estilete e estigma; h. fruto maduro; i. detalhe do indumento no fruto maduro; j. secção transversal do fruto maduro (a-g Farney et al. 858; h-j Farney et al. 859).

Figure 1 - Symplocos neblinae Maguire \& Steyerm. - a. flowering branch; b. detail of the indument on the young leaf; c. detail of the indument on the branches; d. flowering bud; e. corola with epipetalous stamens; f. cross section of the ovary; g. ovary, style, and stigma; h. mature fruit; i. detail of the indument on the mature fruit; j. cross section of the mature fruit (a-g Farney et al. 858 ; h-j Farney et al. 859). 
Material examinado: AMAZONAS: Parque Nacional do Pico da Neblina, Pico da Neblina, entre 2.300 e 2.600 m, 21.VIII.1985, fl., C. Farney et al. 858 (RB); marco BB5, 2.450 m, 21.VIII.1985, fr., C. Farney et al. 859 (INPA, MO, RB).

Material adicional examinado: VENEZUELA. AMAZONAS: Cerro de la Neblina, camp 7, Cañon Grande, 1.770-1.850 m, 30.XI.1984, fl., T.B. Croat
59503 (F, US); Río Yatua, along west escarpment, summit 1.700-2.000 m, 6.I.1954, fl. e fr., B. Maguire et al. 37080 (F, NY, US); Northwest Escarpment, summit 1.700-2.000 m, 10.I.1954, fl. e fr., B. Maguire et al. 37185 (NY, US); trail camp to North Escarpment, 17.XI.1957, fl., B. Maguire et al. 42127 (F, GH, NY, US); along west escarpment, summit $1.800-1.900 \mathrm{~m}$, 17.XI.1957, fl., B. Maguire et al. 42138 (F, NY, US).

\section{Chave de identificação para as espécies deSymplocos sérieSymplocos ocorrentes na Região Norte do Brasil}

1. Ramo esparso a densamente ferrugíneo-piloso; estilete densamente viloso na metade proximal; drupa globosa ou subglobosa, raramente elipsóide S. guianensis

1'. Ramo glabro a densamente dourado-, avermelhado- ou alvo-estrigiloso; estilete glabro ou esparsamente pubescente somente na base; drupa elipsóide, largo-elipsóide, elipsóide-cilíndrica, obovóide ou raramente subclaviforme.

2. Hipanto densamente alvo-estrigiloso; estilete 0,9-1,5(-2) mm compr; drupa esparsamente alvoestrigilosa S. neblinae

2'. Hipanto glabro; estilete 4,3-8 mm compr.; drupa glabra.

3. Folhas com margem conspicuamente serreada/crenada nos $3 / 4$-distais; tubo estaminal 4-6,5 mm compr.; ápice do fruto (3-)3,5-6 mm diâm.; Amapá S. martinicensis

3'. Folhas com margem inteira a esparsamente serrilhada/crenada na metade distal; tubo estaminal 0,3-2 mm compr.; ápice do fruto 2,4-3 mm diâm.; Amazonas e Tocantins S. nitens

Ressaltamos que estamos considerando Symplocos ulei Brand (que ocorreria no Brasil) sinônimo de $S$. guianensis, mas especialistas na família divergem ou não em sinonimizar ambos os nomes. A principal diferença estaria no número de carpelos: quatro em $S$. ulei e cinco em $S$. guianensis. Apesar desta característica ser relevante e frequentemente utilizada na taxonomia da série, às vezes esse caráter pode não ser informativo para separar espécies. No caso de $S$. guianensis, observamos flores com três a cinco carpelos no mesmo espécime.

De acordo com Steyermark \& Berry (2005), Symplocos neblinae ocorre em matas nebulares ou em savanas arbustivas úmidas entre 1.770 e 2.200 $\mathrm{m}$ de altitude no Cerro de la Neblina. Os exemplares coletados pelo segundo autor do presente trabalho cresciam nas encostas que ladeiam o Pico da Neblina na sua face norte, próxima a divisa com a Venezuela, entre 2.300 e $2.600 \mathrm{~m}$ de altitude.

A vegetação da localidade é arbustiva densa e ocorre sobre solo turfoso nas áreas com declives menos acentuados, enquanto nos declives acentuados próximos ao afloramento do Pico, o solo é raso, pedregoso e turfoso, e a vegetação arbustiva torna-se esparsa e a fisionomia sendo dominada por espécies de Eriocaulaceae, Cyperaceae, Poaceae, Xyridaceae e Bromeliaceae. No mapeamento da vegetação da região do Pico da Neblina, Huber (1995) classifica essas formações, respectivamente, como formações arbustivas ("arbustales altotepuyanos bajos, sobre turba") e herbáceas ("herbazales tepuyanos e altotepuyanos de hoja ancha, arbustivos, sobre turba").

Pela morfologia foliar e da inflorescência a espécie mais próxima de Symplocos neblinae é $S$. chimantensis Steyerm. \& Maguire, táxon raro e endêmico do Torono-tepuí, Maciço Chimantá, Venezuela (Steyermark \& Berry 2005). Symplocos chimantensis, no entanto, possui lobos da corola com 10-12,5 mm compr., ovário pentalocular e estilete com aproximadamente $8,5 \mathrm{~mm}$ de comprimento.

\section{Agradecimentos}

Aranha Filho é grato ao Conselho Nacional de Desenvolvimento Científico e Tecnológico 
(CNPq) e à Lakeside Foundation, respectivamente, pela bolsa de doutorado e pela visita de oito meses à California Academy of Sciences. Cyl Farney C. de Sá agradece ao Exército Brasileiro $/ 1^{\circ}$ Batalhão de Forças Especiais a participação na expedição ao Pico da Neblina. Agradecemos também às equipes dos herbários A, BHCB, BM, C, CAS, DS, ESA, F, GH, HRCB, IAC, K, MBM, NY, OUPR, RB, SP, SPF, UEC, UPCB, UPRRP e US o acesso às coleções; aos revisores anônimos os importantes comentários; e à Maria Alice de Rezende a ilustração.

\section{Referências}

Aranha Filho, J.L.M.; Fritsch, P.W.; Almeda, F. \& Martins, A.B. 2007. A revision of Symplocos Jacq. section Neosymplocos Brand (Symplocaceae). Proceedings of the California Academy of Sciences 58: 407-446.

Bidá, A. 1995. Revisão taxonômica das espécies de Symplocos Jacq. (Symplocaceae) do Brasil. Tese de Doutorado. Universidade de São Paulo, São Paulo. 381p.

Fritsch, P.W.; Kelly, L.M.; Wang, Y.; Almeda, F. \& Kriebel, R. 2008. Revised infrafamilial classification of Symplocaceae based on phylogenetic data from DNA sequences and morphology. Taxon 57: 823-852.

Hickey, L.J. 1973. Classification of the architecture of dicotyledonous leaves. American Journal of Botany 60: 17-33.
Hickey, M. \& King, C. 2000. The Cambridge illustrated glossary of botanical terms. Cambridge University Press, Cambridge. 208p.

Huber, O. 1995. Vegetation. In: Berry, P.E.; Yatskievych, K. \& Holst, B.K. (eds.). Flora of the Venezuelan Guayana. Vol. 1. Introduction. Missouri Botanical Garden Press, St. Louis. Pp. 97-160.

Maguire, B. \& Huang, Y.C. 1978. Symplocaceae. In: Maguire, B. \& colls. The botany of the Guayana highland. Part X. Memoirs of the New York Botanical Garden 29: 223-230.

Maguire, B. \& Wurdack, J.J. 1959. The position of Cerro de la Neblina, Venezuela. Geographical Review 49: 566-569.

Renner, S.S. 1989. Floral biological observation on Heliamphora tatei (Sarraceniaceae) and others plants from Cerro de la Neblina in Venezuela. Plant Systematics and Evolution 163: 21-29.

Steyermark, J.A. \& Berry, P.E. 2005. Symplocaceae. In: Berry, P.E.; Yatskievych, K. \& Holst, B.K. (eds.). Flora of the Venezuelan Guayana. Vol. 9. RutaceaeZygophyllaceae. Missouri Botanical Garden Press, St. Louis. Pp. 290-295.

Thiers, B. 2010 [continuously updated]. Index Herbariorum: A global directory of public herbaria and associated staff. New York Botanical Garden's Virtual Herbarium. Disponível em <http://sweetgum. nybg.org./ih>. Acesso em janeiro 2010. 